Check for updates

Cite this: Phys. Chem. Chem. Phys., 2020, 22, 20829

Received 8th April 2020

Accepted 22nd August 2020

DOI: $10.1039 / \mathrm{d} 0 \mathrm{cp} 01917 \mathrm{~h}$

rsc.li/pccp

\title{
Molecular dynamics simulation of soot formation during diesel combustion with oxygenated fuel addition
}

\author{
Cheng Chen and Xi Jiang (D)
}

\begin{abstract}
This study investigates the soot formation process of diesel combustion using molecular dynamics simulations with reactive force fields by examining the effects of five oxygenated additives on diesel soot reduction. The newly improved ReaxFF CHO2016 parameters are employed due to their feasibility in modelling the kinetics of large hydrocarbon fuels and describing the chemistry of carbon condensed phases. The detailed pathways of soot formation examined include the thermal decomposition of fuels, the formation of aromatic rings, the mechanism of nucleation, and the mass growth of nascent soot. The morphological developments of the soot formation are obtained, together with quantities indicating the physical and chemical properties, such as mass, size, $\mathrm{C}: \mathrm{H}$ ratio and aliphatic-to-aromatic $\mathrm{C}: \mathrm{H}$ ratio. The role of aliphatic-substituted aromatics in nascent soot coalescence and the appearance of aliphatic side chains in soot structures are identified. The concentrations of C-atoms in nascent soot particles contributed from oxygenates blended with diesel are quantified and visualized for the first time. The effects of the molecular structure of the oxygenated additives, i.e. the existence of esters, alcohols, carbonyl groups and ethers, on soot precursor mitigation are elucidated by evaluating the early formation of $\mathrm{CO}$ and $\mathrm{CO}_{2}$ quantitatively during the thermal decomposition.
\end{abstract}

\section{Introduction}

Airborne particulate matter such as soot is of major environmental concern and can affect public health. Diesel combustion is known to be the main contributor to soot emission. Among various advanced control strategies and combustion techniques developed to reduce soot emission from diesel combustion, modifying fuel composition by blending the fuel with renewable oxygenated additives has drawn particular attention due to the potential of tackling the problem both ecologically and economically. ${ }^{1}$ Although previous work has shown that the oxygen contents in fuel composition have a major influence on soot production (when the oxygen content of the fuel reached $25-30 \%$ by mass, all soot emissions virtually vanished ${ }^{2}$ ), the chemical mechanisms involved in the soot reduction process are not well understood because of the complicated fuel molecular structure and the lack of in-depth kinetics studies. There has been no clear agreement on the impact of the oxygenated functionalities, e.g., alcohols, esters, and carbonyl groups, on the soot reduction process, nor on the mechanisms involved. ${ }^{3}$ This motivates the present study to

School of Engineering \& Materials Science, Queen Mary University of London, London E14NS, UK. E-mail: xi.jiang@qmul.ac.uk reveal the effect of the specific molecular structure of oxygenates on diesel soot suppression.

Understanding the soot formation mechanism and thereby reducing soot emissions from combustion devices have always been a challenge. It is acknowledged that soot nucleation defined as the transition from gaseous molecular precursors to condensed matter, yielding carbonaceous nanoparticles, is a key step but mostly unknown. ${ }^{4}$ Critical gaps remain between the experimental observation and mechanistic description. ${ }^{5}$ The widely reported soot nucleation pathway involving the dimerization of polycyclic aromatic hydrocarbons (PAHs) into stacks via van der Waals forces is debatable. ${ }^{6}$ It fails to explain, for example, the existence of a large amount of aliphatic $\mathrm{C}-\mathrm{H}$ bonds in the shell of nascent soot. ${ }^{7}$ The irreversible process of PAH dimerization, with pyrene $\left(\mathrm{C}_{16} \mathrm{H}_{10}\right)$ recognized as the smallest building block, is not thermodynamically favoured. ${ }^{8}$ The binding forces (e.g., electrostatic, dispersive and $\pi-\pi$ stacking interaction forces) of dimers with moderate-sized PAHs are too weak to allow the PAH clusters to survive in the environment above their boiling or sublimation temperatures. The species as large as ovalene $\left(\mathrm{C}_{32} \mathrm{H}_{14}\right)$, hexcoronene $\left(\mathrm{C}_{42} \mathrm{H}_{18}\right)$ or circumcoronene $\left(\mathrm{C}_{54} \mathrm{H}_{18}\right)$ may generate dimers capable of surviving at flame temperature. The concentration of these $\mathrm{PAH}$ species in the gas phase during combustion is low, which is contradictory to the phenomenon that nascent soot was observed before the 
concentration peaks of these PAH species. ${ }^{9}$ The hypothesis of the dimerization of PAHs with a larger size in the soot nucleation process therefore appears highly unlikely. It is speculated that some stronger interactions are prerequisite for soot nucleation, such as covalent bonds combining $\mathrm{PAH}$ radicals and aryl radicals, but the existing theories are still inadequate to explain the rapidly persistent mass growth and the gas-to-solid nucleation process in the post flame region. ${ }^{5}$ In general, although the conceptual pathways of nucleation in the existing theory are feasible and important, chemical pathways besides physical stacking are needed to achieve a comprehensive and accurate understanding of soot formation.

The availability of modelling/simulation tools at the atomistic level may shed light on these unsolved issues. The multiscale model for soot inception developed by Violi et al., ${ }^{10}$ integrating kinetic Monte Carlo and molecular dynamics (MD), allows the extension of the accessible time scale by orders of magnitude while retaining the full atomistic details. Application of this model to acetylene and benzene flames showed that the reaction pathways concerning the growth of incipient soot particles are dependent on the molecular structure of the fuel. Some indicators were employed to evaluate the properties of the three-dimensional structure of nascent soot particles including physical properties (e.g., porosity, density, radial distribution function and sphericity) and chemical properties (e.g., $\mathrm{C}: \mathrm{H}$ ratio, aromatic moieties and number of crosslinks). ${ }^{11,12}$ MD simulation with the OPLS-AA force field ${ }^{13,14}$ was used to quantify the impact of the mass, symmetry and morphology of peri-condensed aromatic hydrocarbons (PCAHs), aromatic aliphatically linked hydrocarbons (AALHs) and aliphatic substituted PAHs on the stability of the molecular dimers. Meanwhile, the contributions from potential energy and entropy were taken into consideration simultaneously by using the free energy methods to describe the process. It was understood that the attached aliphatics increased the nucleation rate greatly due to the collision energy accommodation enhancement provided by the added internal degrees of freedom. Modelling work was also performed by using replica exchange MD simulation to investigate the molecular size distributions of the heterogeneous PAH clusters in a core-shell model. ${ }^{15}$ It was found that larger PAHs are stacked at the core while small PAHs are located on the cluster surface. Of the two main factors, the strength of intermolecular interactions played a more critical role in determining cluster partition than the molecular size difference. Another method for modelling the combustion and soot formation process is reactive force field (ReaxFF) based MD simulations. For example, Mao et al. ${ }^{16-18}$ found that physical dimerization depended on both the temperature and PAH size while all the PAHs became chemically active at temperatures above $2500 \mathrm{~K}$ and generated fullerenelike soot particles. It is recognized that MD-type modelling/ simulation will likely lead to high-fidelity soot models capable of simultaneously resolving particle size distribution, chemical composition, and morphology. $5,10,16$

The improved CHO2016 parameters in ReaxFF have been successfully used to investigate the combustion kinetics of conventional fuels like syngas, ethanol, JP-10, and toluene. ${ }^{19-21}$ Most importantly, the CHO2016 description is also trained from C2013 parameters that are able to describe the chemistry of aromatic hydrocarbons properly in condensed and gaseous phases simultaneously. ${ }^{16,19,22}$ Therefore, we perform ReaxFF MD simulation in a single force field without any predefined radicals or reaction pathways to reveal the role of fuel molecular structure on soot formation, which was previously inaccessible using existing computational chemistry methods.

\section{Simulation methodology}

\subsection{Simulation setup}

In this study, a recently proposed 5-component diesel surrogate fuel by Qian et $a l^{23}$ is employed to simulate diesel soot formation, which can accurately reproduce the gaseous emissions of the target diesel fuel under actual engine combustion conditions. The surrogate fuel shown in Fig. 1(a) includes $21.6 \% n$-hexadecane $\left(n\right.$-HXD, $\left.\mathrm{C}_{16} \mathrm{H}_{34}\right), 15.5 \%$-octadecane (n-OTD, $\mathrm{C}_{18} \mathrm{H}_{38}$ ), 26.0\% heptamethylnonane ( $\mathrm{HMN}, \mathrm{C}_{16} \mathrm{H}_{34}$ ), $20.7 \%$ 1-methylnaphthalene (1-MNT, $\mathrm{C}_{11} \mathrm{H}_{10}$ ) and $16.2 \%$ decalin $\left(\mathrm{C}_{10} \mathrm{H}_{18}\right)$ by mol. Five representative oxygenates, i.e., dimethyl carbonate (DMC, $\mathrm{C}_{3} \mathrm{H}_{6} \mathrm{O}_{3}$ ), cyclopentanone (CPO, $\left.\mathrm{C}_{5} \mathrm{H}_{8} \mathrm{O}\right)$, methyl butanoate $\left(\mathrm{MB}, \mathrm{C}_{5} \mathrm{H}_{10} \mathrm{O}_{2}\right)$, dimethoxymethane (DMM, $\left.\mathrm{C}_{3} \mathrm{H}_{8} \mathrm{O}_{2}\right)$ and ethanol $\left(\mathrm{C}_{2} \mathrm{H}_{6} \mathrm{O}\right)$, shown in Fig. $1(\mathrm{~b})$, are selected to blend with diesel surrogates so as to evaluate the effects of ketones, esters, ethers and alcohols on soot precursor mitigation.

The reactive systems studied are shown in Table 1 . System 1 is established as a baseline containing 149 pure diesel surrogate molecules with 150 oxygen molecules to model the fuel-rich
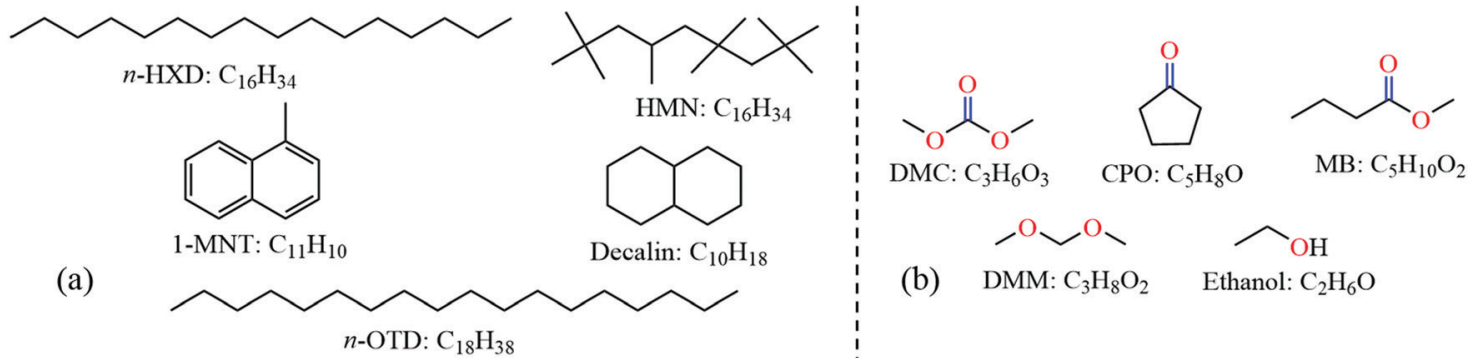

Fig. 1 Molecular structures and chemical formulas of (a) the diesel surrogate fuel and (b) oxygenated fuel additives. 
Table 1 Number of molecules of diesel surrogate fuel and oxygenated additives in the simulation box

\begin{tabular}{lllllll}
\hline System no. & $n$-HXD & HMN & 1-MNT & Decalin & $n$-OTD & Additives \\
\hline 1 & 32 & 39 & 31 & 24 & 23 & O2: 150 \\
2 & 27 & 34 & 27 & 21 & 20 & DMC: 100 \\
3 & 9 & 12 & 9 & 7 & 7 & CPO: 300 \\
4 & 25 & 31 & 24 & 19 & 18 & DMM: 150 \\
5 & 21 & 25 & 20 & 16 & 15 & MB: 150 \\
6 & 23 & 28 & 22 & 17 & 17 & Ethanol: 300
\end{tabular}

combustion. To study the effect of fuel additives, oxygenated fuel molecules are doped into the simulation boxes containing the diesel model. A rule is adopted in which systems $2-6$ are set up by adjusting the number of diesel molecules in the box so that these systems have approximately the same carbon and oxygen numbers as system 1 . This could highlight the influence of the molecular structure of the additive instead of the amount of oxygen. The density of system 1 is set to be $0.1 \mathrm{~g} \mathrm{~cm}^{-3}$, and the edge length of the cubic box is $82.5 \AA$. The size of the simulation boxes in systems 2-6 is adjusted accordingly to have the same density as system 1 .

\subsection{Simulation details}

The simulation is performed using the constant temperature canonical ensemble, i.e. the NVT ensemble. The periodic boundary conditions are imposed in all three directions. Before the production run, every system undergoes energy minimization and equilibration at $1000 \mathrm{~K}$ for $50 \mathrm{ps}$. After the equilibration, a series of reactive $N V T$ MD simulations for each system is performed for $2 \mathrm{~ns}$ at $3000 \mathrm{~K}$. The system temperature is controlled by a Nosé-Hoover thermostat algorithm with a damping constant of $25 \mathrm{fs}$. In ReaxFF simulations, employing high temperature and pressure to facilitate the collision and accelerate the simulation process is a common strategy. ${ }^{19,20,24,25}$ A time step of $0.25 \mathrm{fs}$ is adopted for both the equilibrating and reactive simulations. The species information is recorded every $100 \mathrm{fs}$ while dynamic trajectory and bonding information is dumped every 250 fs. For intermediate and product recognition analysis, a 0.3 bond order cut-off is chosen to capture all the chemical reaction pathways including those with short-lived intermediates. ${ }^{21}$ All the simulations are carried out with the REAXC package in the LAMMPS platform ${ }^{26}$ with force field parameters modified accordingly. The reaction pathways are analysed using Chemical Trajectory AnalYzer scripts. ${ }^{27}$ The visualisation of simulation results is carried out using Visual Molecular Dynamics software. ${ }^{28}$

\section{Results and discussion}

\subsection{Incipient soot formation mechanism of diesel combustion}

Force field parameters play a key role in the capability of MD simulations. Between the two sets of widely used reactive force field parameters for combustion simulation, $\mathrm{CHO} 2016$ retains the capability of $\mathrm{CHO} 2008$ for predicting complex hydrocarbon pyrolysis and oxidation reactions but has taken into account more chemical pathways with improved accuracy ${ }^{19}$ that are

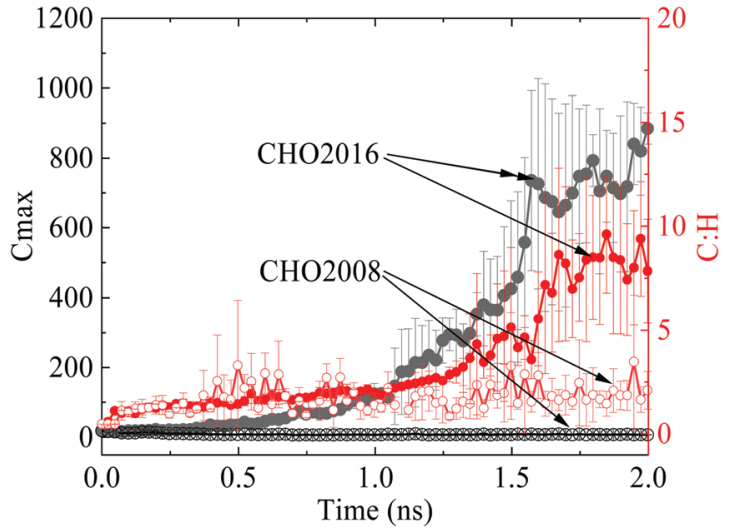

Fig. 2 Evaluation of $\mathrm{CHO} 2008$ and $\mathrm{CHO} 2016$ force field parameters in predicting diesel incipient soot formation in terms of the number of carbon atoms in the largest molecule and the $\mathrm{C}: \mathrm{H}$ ratio of the largest molecule, where the solid cycle represents $\mathrm{CHO} 2016$ while the hollow cycle represents $\mathrm{CHO} 2008$.

important for soot formation. The feasibility of the two sets of parameters in predicting particle growth during the soot inception process is evaluated first, as shown in Fig. 2. The carbon number of the largest particle in $\mathrm{CHO} 2016$ can be as large as 1000 at the subsequent steady mass growth stage after the initial fuel decomposition, whereas $\mathrm{CHO} 2008$ fails to predict the particle growth with the carbon number remaining at an extremely low level. After $1.6 \mathrm{~ns}$, the $\mathrm{C}: \mathrm{H}$ ratio of the largest molecule in $\mathrm{CHO} 2016$ starts to increase and becomes much higher than that of $\mathrm{CHO} 2008$, which is as one would have expected, indicating that $\mathrm{CHO} 2016$ is able to describe the continuous dehydrogenation reasonably during soot inception. As a consequence, $\mathrm{CHO} 2016$ parameters are employed in the following simulations.

The time evolutions of the regular products of diesel combustion, e.g., $\mathrm{CO}, \mathrm{CO}_{2}, \mathrm{H}_{2} \mathrm{O}$ and formaldehyde $\left(\mathrm{CH}_{2} \mathrm{O}\right)$, are shown in Fig. 3(a), and those of the typical $\mathrm{C}_{1}-\mathrm{C}_{3}$ intermediates like the methyl radical $\left(\mathrm{CH}_{3}\right)$, ethylene $\left(\mathrm{C}_{2} \mathrm{H}_{4}\right)$, ethyne $\left(\mathrm{C}_{2} \mathrm{H}_{2}\right)$, vinyl $\left(\mathrm{C}_{2} \mathrm{H}_{3}\right)$ and propargyl $\left(\mathrm{C}_{3} \mathrm{H}_{3}\right)$ are displayed in Fig. 3(b). Visualisation and identification of the representative molecular structures are captured and presented in Fig. 4. In fuel-rich combustion, $\mathrm{O}_{2}$ is consumed at an extremely high rate at the initial stage accompanying the acute increase of $\mathrm{CO}$ molecules. The formation of $\mathrm{CO}_{2}$ occurs around 1.8 ps later compared to $\mathrm{CO}$ because of its dependence on the production of $\mathrm{C}_{1}$ species like $\mathrm{CO}, \mathrm{HCO}$, and $\mathrm{CH}_{2} \mathrm{O}$. Only around $6 \mathrm{CO}_{2}$ molecules are produced, which is a rather small volume compared with $\mathrm{CO}$. The amount of $\mathrm{CO}_{2}$ molecules remained almost constant in this period, manifesting that no $\mathrm{CO}$ has been further converted into $\mathrm{CO}_{2} \cdot \mathrm{H}_{2} \mathrm{O}$ production takes place earlier than $\mathrm{CO}_{2}$ production in an appreciable quantity. The formaldehyde molecule is also found to be an important intermediate and it reaches a maximum number of 92 at 29.1 ps. The existence of the formaldehyde peak is a feature of the low-temperature combustion of large alkanes. At temperatures as high as $3000 \mathrm{~K}$, it is unstable and would decompose to $\mathrm{CO}$ easily, which explains the steady increase of $\mathrm{CO}$ at the late stage. 


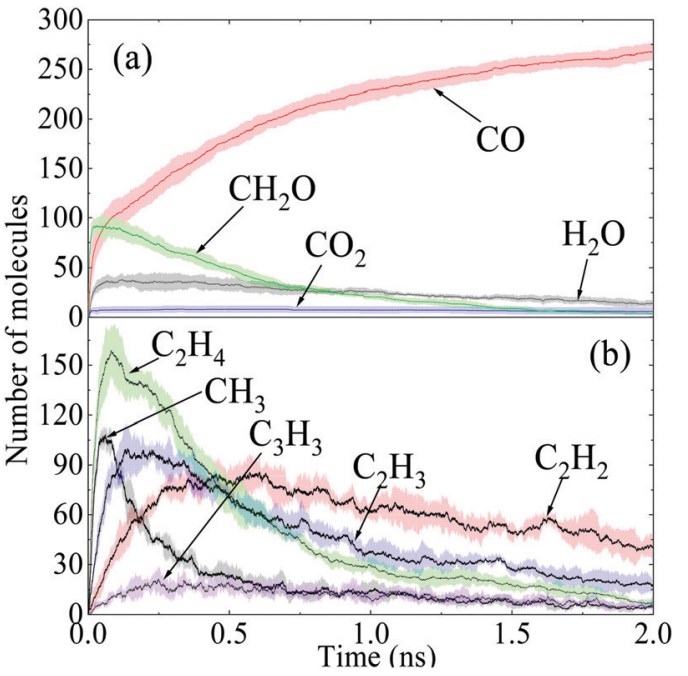

Fig. 3 Time evolutions of major intermediates and products in diesel combustion, where the shaded area indicates the average standard deviations of five repeated simulations.

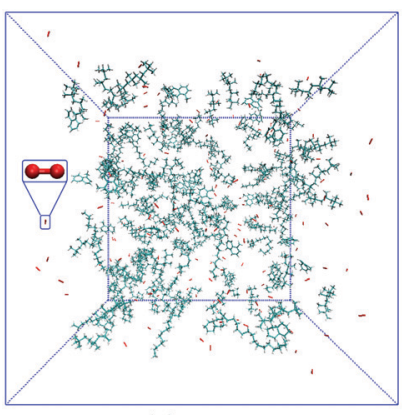

(a) $0 \mathrm{~ns}$

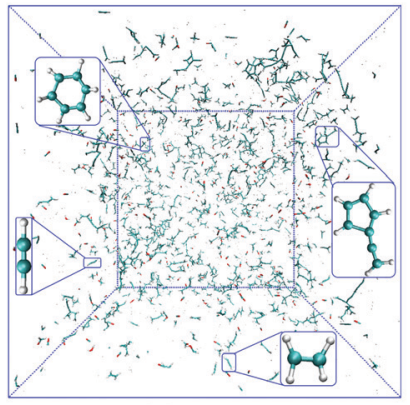

(c) $0.5 \mathrm{~ns}$

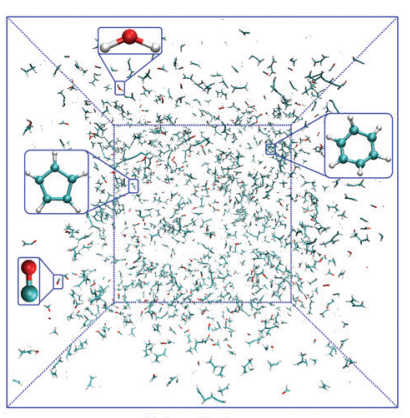

(b) $0.1 \mathrm{~ns}$

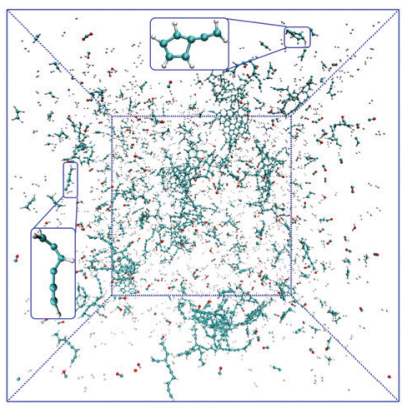

(d) $1.3 \mathrm{~ns}$
Fig. 4 Time evolutions of incipient soot formation of diesel combustion, where $\mathrm{C}, \mathrm{H}$ and $\mathrm{O}$ atoms are represented in cyan, silver and red, respectively.

In Fig. 3(b), the number of ethylene molecules decreases immediately after reaching its maximum at around $80.8 \mathrm{ps}$ while the peaks of ethyne and the vinyl radical are relatively inconspicuous. Ethyne, the vinyl radical and the propargyl radical can persist throughout the whole process, whereas the methyl radical and ethylene deplete almost completely at the late stage. This is mainly because paraffins like $n$-HXD and $n$-OTD accounting for the largest proportion of the diesel composition would experience $\mathrm{H}$-abstraction and consecutive unimolecular $\mathrm{C}-\mathrm{C}$ fission to produce alkyl radicals like $\mathrm{C}_{4} \mathrm{H}_{9}$, $\mathrm{C}_{7} \mathrm{H}_{15}, \mathrm{C}_{8} \mathrm{H}_{17}$ and $\mathrm{C}_{13} \mathrm{H}_{27}$, releasing ethylene at the same time. ${ }^{29}$ A series of $\beta$-scission reactions of these $\mathrm{C}_{4}-\mathrm{C}_{13}$ fragments takes place subsequently to form alkenes. HMN tends to produce more of the large alkenes as it is more likely to dissociate to alkyl radicals with substitution at the $\beta$ C-atom. Ethylene mainly reacts into ethyne and the vinyl radical while the propargyl radical is produced from the dehydrogenation of propene via a series of $\mathrm{H}$-abstractions with $\mathrm{H}$-atom as the primary abstractor. ${ }^{30}$ The propargyl radical is a kind of resonantlystabilized radical (RSR), which would undergo decomposition and oxidation at much lower rates than nonresonant radicals do. These $\mathrm{C}_{2}$ and $\mathrm{C}_{3}$ unsaturated hydrocarbons play crucial roles in cyclopentadienyl and benzene formation whilst the specific pathways vary considerably. Another observation is that the large aliphatics are repolymerized by a wide variety of these precursors and alkenes after the depletion of the initial diesel alkanes, and the relevant molecular structures are captured and illustrated in Fig. 4(d).

Hydrocarbon combustion is triggered either by unimolecular $\mathrm{C}-\mathrm{C}$ bond dissociation or the oxidative reaction via the abstraction of a hydrogen free radical from the substrate. In this study, the earliest reaction of 1-MNT detected is the $\mathrm{H}$-abstraction reaction by $\mathrm{O}_{2}$ through cleavage of the $\mathrm{C}-\mathrm{H}$ bond in the methyl group at $0.3 \mathrm{ps}$, producing the hydroxyl radical and the corresponding 1-naphthylmethyl radical. This is ascribed to the relatively low dissociation energy of the methyl $\mathrm{C}-\mathrm{H}$ bond, i.e., $85.1 \mathrm{kcal} \mathrm{mol}{ }^{-1}{ }^{31}$ The aromatics are generally stable and can survive a long time before the ring-opening reactions. In this period, it is possible to break the methyl-aryl C-C bond and the aryl $\mathrm{C}-\mathrm{H}$ bond. These decomposition reactions would favour the formation of the 1-MNT radical and naphthalene radical. Moreover, the 2-methylindene radical with a pentagonal ring is also observed. The early formation of these aryl groups, with molecular structures and highlighted radical sites displayed in Fig. 5(a), was also observed experimentally by Shaddix et al. ${ }^{32}$ They are regarded as potential building blocks with high propensity to produce nascent soot by reacting with additional benzenoid rings. Thus, the soot precursor formation mechanism is closely correlated with the fuel molecular structures, particularly the large hydrocarbons existing in practical fuels that can decompose in a wide range of pathways.

In this study, the initial mass growth is found to be triggered by the addition of $\mathrm{C}_{2} \mathrm{H}_{2}$ or $\mathrm{C}_{2} \mathrm{H}_{3}$ to cyclopentadienyl and benzene. The newly generated RSRs are constructed by five-, six- or seven-membered carbon rings substituted with unsaturated aliphatics, as shown in Fig. 4(c) and 5(b). More recently, the aliphatic-substituted aromatics in nascent soot particles were observed and visualized directly via high-resolution atomic force microscopy. ${ }^{33}$ The small aliphatics would connect the RSRs via a chemical covalent bond, dimerizing into cross-linked threedimensional AALH structures, as shown in Fig. 5(d). The unstable AALH structures further evolve into a peri-condensed plane through rearrangement and ring closure, ${ }^{9}$ leading to aromatic peri-condensed polycyclic hydrocarbon (APPH) structures at $1.5 \mathrm{~ns}$. An aromatic directly linked hydrocarbon (ADLH) 


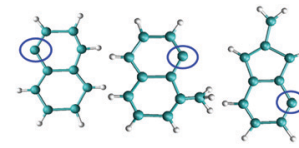

(a) $2.5 \mathrm{ps}$

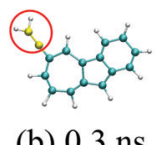

(b) $0.3 \mathrm{~ns}$

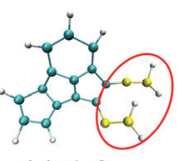

(c) $1.0 \mathrm{~ns}$

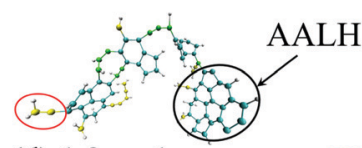

(d) $1.3 \mathrm{~ns}-1$ $\mathrm{C}_{147} \mathrm{H}_{70}$

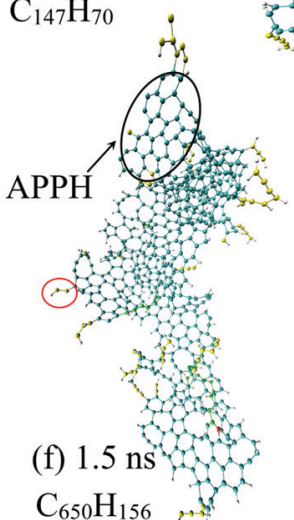

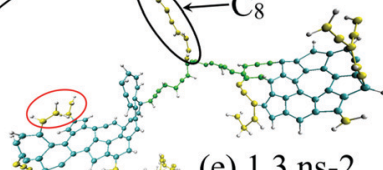

(e) $1.3 \mathrm{~ns}-2$ $\mathrm{C}_{397} \mathrm{H}_{137}$

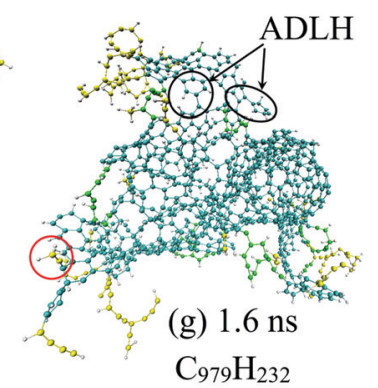

Fig. 5 Snapshots of the enlarged representative carbonaceous nanoparticle morphology during diesel combustion, where aliphatic side chains are coloured in yellow with direct $\mathrm{C}_{2} \mathrm{H}_{2}$ or $\mathrm{C}_{2} \mathrm{H}_{3}$ addition highlighted with a red ellipse, while aliphatic links between aromatic moieties in nascent soot are highlighted in green.

is also observed at around 1.6 ns. In this period, addition reactions also take place in the hydrocarbon flame, generating the elongated aliphatic side chains, e.g., $\mathrm{C}_{8}$ alkene, as shown in Fig. 5(e). The flat size of incipient soot can have a length of
$6.03 \mathrm{~nm}$, as shown in Fig. 5(f). At high temperature, it would undergo cyclization and condensation, resulting in a branched fullerene/ellipsoid structure. The morphology of the nascent soot at $1.6 \mathrm{~ns}$ is an amorphous structure, around $3.7 \mathrm{~nm}$ in diameter and 998 amu in mass, rich in aliphatics, with a $\mathrm{C}: \mathrm{H}$ ratio of $6-10$. The ratio of $\mathrm{C}-\mathrm{H}$ groups present in aliphatics to that in aromatic rings is around 1.2 at $1.6 \mathrm{~ns}$ and 2.3 at $2 \mathrm{~ns}$, respectively. In addition, it can be assumed that aliphaticsubstituted aromatics can also act as building blocks to stack into the outer shell when the temperature becomes somewhat lower. RSR moieties on shell surfaces could provide sites for small hydrocarbons in flames to attach. This pathway could potentially explain recent experimental results showing that the soot shell surface is abundant with alkyl or alkenyl functionalities in the range of $\mathrm{C}_{2}-\mathrm{C}_{8}{ }^{5}$

\subsection{Soot formation during diesel combustion with blending of oxygenates}

In this study, the blending ratio was configured properly to unify the oxygen contents and the overall carbon quantity to highlight the effect of oxygenate molecular structure on the soot formation process. Some insights into the soot inception of diesel with oxygenates can be gained from the detailed morphological development comparison, as shown in Fig. 6 at the time instants of $1.2 \mathrm{~ns}$ and $2 \mathrm{~ns}$, respectively. The C-atoms contributed from the oxygenates are quantified and highlighted in the nascent soot.

In Fig. 6, both the morphology of the nascent soot and the number of C-atoms from oxygenates vary in different cases, among which C-atoms from DMC only account for 5.9\% (calculated from 18/304) and 5.7\% (from 46/814) at 1.2 ns and 2 ns, respectively, as shown in Fig. 6(a), while almost $73.8 \%$ and $67.0 \%$ of the C-atoms are from CPO at 1.2 ns and 2 ns, as shown

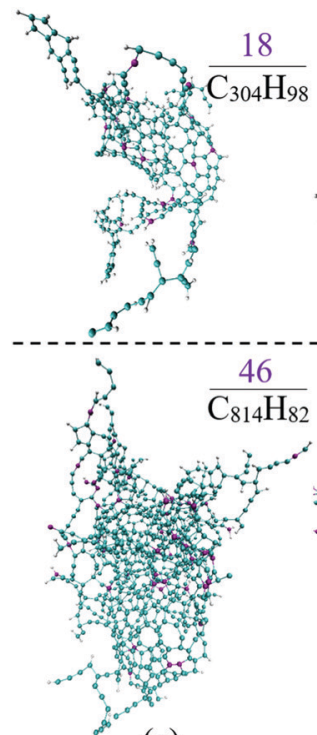

(a)
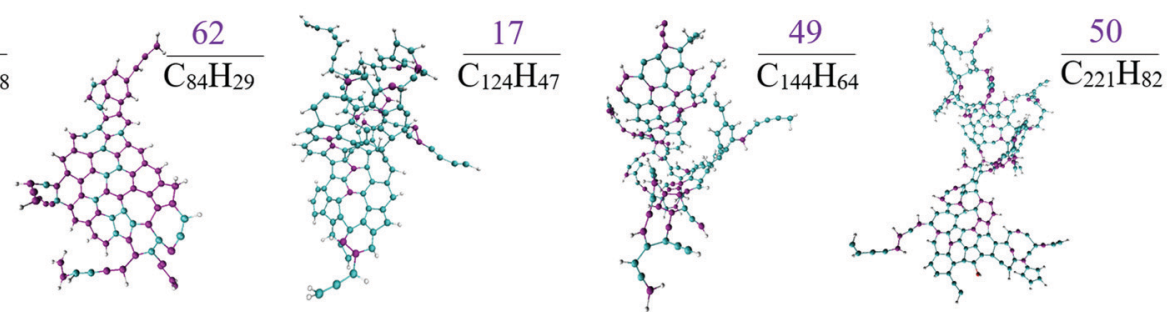

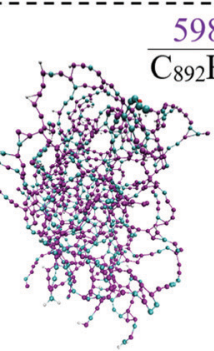

(b)

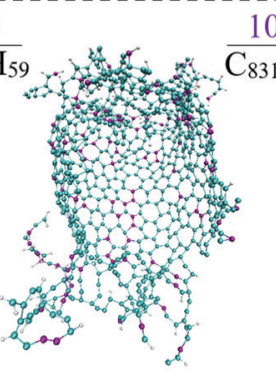

(c)

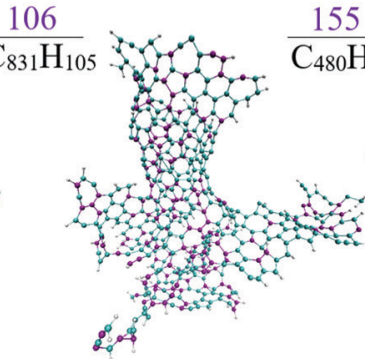

(d)

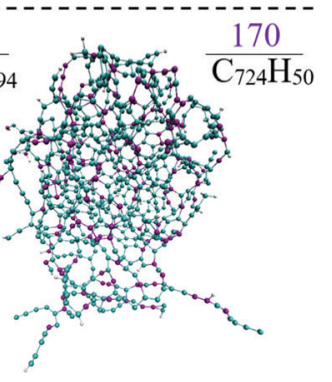

(e)

Fig. 6 Morphological snapshots of nascent soot at 1.2 ns (above the dashed line) and final soot particles at 2 ns (below the dashed line) in diesel combustion with various additives, from left to right: (a) DMC, (b) CPO, (c) DMM, (d) MB and (e) ethanol, where the numbers of carbon atoms contributed from oxygenated fuel additives are given in purple. 
in Fig. 6(b). This is mainly attributed to the initial configuration, which was determined by the $\mathrm{C}: \mathrm{O}$ ratio of the oxygenate molecular structures. It is more meaningful to compare the $\mathrm{C}$-atom ratio originating from oxygenated additives in nascent soot with the corresponding initial stoichiometric configuration to evaluate the sooting propensity of oxygenates. For the cases of diesel blending with DMC and DMM, the C-atom contribution ratios at $2 \mathrm{~ns}$ are $5.7 \%$ and $12.8 \%$, respectively, both of which are much smaller than the $\mathrm{C}$-atom ratio between oxygenates and fuel mixtures in the initial box, which are $14.0 \%$ and $21.2 \%$, respectively. This means that DMC and DMM are much less likely to form the nascent soot compared with diesel surrogate molecules. The ratios for cases blending with CPO and ethanol are $67.0 \%$ and $23.5 \%$ in nascent soot, both of which are lower but at almost the same level as the initial ratio, i.e., $70.4 \%$ and $28.1 \%$, respectively. It is thus indicated that CPO and ethanol have similar sooting propensities to diesel. This is also the case for fuel mixtures blending with $\mathrm{MB}$, where $35.1 \%$ of the $\mathrm{C}$-atoms are from $\mathrm{MB}$ in the initial box but the contribution is $32.3 \%$ in the final nascent soot. These observations can be ascribed to the consecutive $\mathrm{C}-\mathrm{C}$ bond in the molecular structures of $\mathrm{CPO}, \mathrm{MB}$ and ethanol, which would lead to soot formation. However, the C-atoms in DMC and DMM are separate and each of them is bound to a different O-atom, avoiding significant levels of the products such as ethylene, acetylene or unsaturated radicals, which are known to be PAH precursors.

\subsection{Quantification of oxygenate effectiveness in soot precursor mitigation}

The effectiveness of oxygenates in soot suppression is not well understood and is attracting increasing interest. ${ }^{34-36}$ In the kinetics modelling performed by Westbrook et $a .^{2}$ for the premixed fuel-rich combustion of $n$-heptane and oxygenate blends, it was observed that all oxygenates tested reduced the emission of soot precursors, but with different effectiveness. In the previous experimental study by Farooq et al., ${ }^{34}$ the effectiveness was represented by the number of C-atoms captured by $\mathrm{CO}$ and $\mathrm{CO}_{2}$. The time histories of $\mathrm{CO}$ and $\mathrm{CO}_{2}$ for the thermal decomposition of oxygenates blended with diesel are presented in Fig. 7. The capability of ReaxFF in capturing chemical reaction pathways and predicting Arrhenius parameters quantitatively has been validated extensively against experiments and continuum methods. ${ }^{19,20}$ It is a common practice to normalize the absolute rate constants using the slowest reaction obtained from ReaxFF simulations, that is, the rate constant of the slowest reaction is set to be $1 .^{24}$ The thermal pyrolysis pathways of the oxygenates and the relative kinetic rates are summarized in Table 2.

Among the additives, CPO shows the best performance with 294 oxygen atoms used to fix $\mathrm{C}$-atoms while $\mathrm{MB}$ has the lowest quantity. This is because the scission of the $\mathrm{C}=\mathrm{O}$ double bonds in the CPO carbonyl group hardly occurs even at $3000 \mathrm{~K}$, and double bonds are maintained all the way to $\mathrm{CO}$ formation through unimolecular decomposition, i.e., $\mathrm{R} 3^{*}$, with a rapid kinetic rate. This also explains the steep increase of $\mathrm{CO}$ in the initial stage of Fig. 7(a) before the turning point at around $0.12 \mathrm{~ns}$. In contrast, $\mathrm{MB}$ has the lowest plateau value for $\mathrm{CO}$ but with a fair

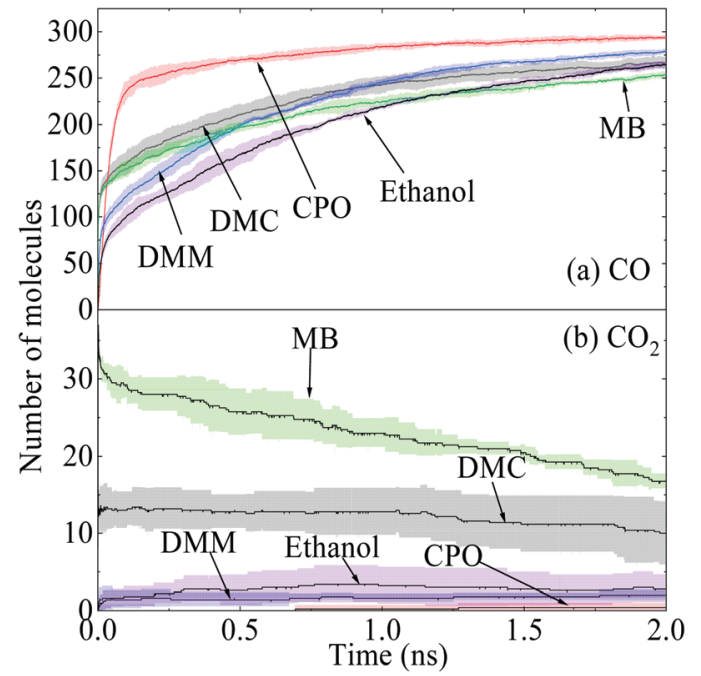

Fig. 7 Time evolutions of (a) $\mathrm{CO}$ and (b) $\mathrm{CO}_{2}$ for diesel blending with various additives at $3000 \mathrm{~K}$

amount of $\mathrm{CO}_{2}$, as demonstrated in Fig. 7(b), indicating that the $\mathrm{CO}_{2}$ moieties in esters tend to result in the direct formation of $\mathrm{CO}_{2}$ molecules considerably. In this way, two O-atoms together captured only one C-atom from the species pool. The oxygen initially present in esters is therefore less effective. As a carbonate ester, the early formation of $\mathrm{CO}_{2}$ was also observed in DMC. Specifically, pyrolysis of DMC and MB by R1 and R11, respectively, can produce a considerable amount of methoxycarbonyl radical, i.e., $\mathrm{CH}_{3} \mathrm{O}\left(\mathrm{C}^{\bullet} \mathrm{O}\right)$, which has two competitive decomposition pathways to produce $\mathrm{CO}_{2}$ or $\mathrm{CO}+\mathrm{CH}_{3} \mathrm{O}$. However, both $\mathrm{CH}_{3} \mathrm{O}(\mathrm{CO}) \mathrm{O}^{\bullet}$ in DMC by $\mathrm{R} 2$ and $\mathrm{CH}_{3}\left(\mathrm{CH}_{2}\right)(\mathrm{CO}) \mathrm{O}^{\bullet}$ in $\mathrm{MB}$ by $\mathrm{R} 10$ are more likely to produce $\mathrm{CO}_{2}$ directly via $\beta$-scission. ${ }^{34}$

Unimolecular decomposition plays a leading role in the pyrolysis of oxygenates while $\mathrm{H}$-abstraction by a H-atom, or a methoxy or hydroxyl radical also accounts for a certain proportion of the

Table 2 Observed primary chemical reaction and relative kinetic rate of oxygenates in thermal decomposition, where the reactions leading to the direct formation of $\mathrm{CO}$ are marked with an asterisk, the products of alkyl radicals are in italics, and the species facilitating the bimolecular decomposition are in bold

\begin{tabular}{|c|c|c|}
\hline ID & Reaction & Relative rate \\
\hline R1 & $\mathrm{DMC} \rightarrow \mathrm{CH}_{3} \mathrm{O}^{\bullet}+\mathrm{CH}_{3} \mathrm{O}\left(\mathrm{C}^{\bullet} \mathrm{O}\right)$ & $(1.01 \pm 0.09) \times 10^{4}$ \\
\hline $\mathrm{R} 2$ & $\mathrm{DMC} \rightarrow \mathrm{CH}_{3}^{\bullet}+\mathrm{CH}_{3} \mathrm{O}(\mathrm{CO}) \mathrm{O}^{\bullet}$ & $(2.44 \pm 0.14) \times 10^{2}$ \\
\hline $\mathrm{R} 3^{*}$ & $\mathrm{CPO} \rightarrow \mathrm{CO}+\mathrm{CH}_{2}^{\bullet}\left(\mathrm{CH}_{2}\right)_{2} \mathrm{CH}_{2}^{\bullet}$ & $(7.99 \pm 0.73) \times 10^{3}$ \\
\hline R4 & $\mathrm{CPO} \rightarrow \mathrm{CH}_{2}^{\bullet} \mathrm{CH}_{2}^{\bullet}+\left(\mathrm{C}^{\bullet} \mathrm{O}\right) \mathrm{CH}_{2} \mathrm{CH}_{2}^{\bullet}$ & $(1.84 \pm 0.12) \times 10^{3}$ \\
\hline R5 & $\mathrm{CPO} \rightarrow \mathrm{CH}_{2}^{\bullet} \mathrm{CH}_{2} \mathrm{CH}_{2}^{\bullet}+\left(\mathrm{C}^{\bullet} \mathrm{O}\right) \mathrm{CH}_{2}^{\bullet}$ & $(4.66 \pm 0.24) \times 10^{2}$ \\
\hline R6 & $\mathrm{DMM} \rightarrow \mathrm{CH}_{3}^{\bullet}+\mathrm{CH}_{3} \mathrm{OCH}_{2} \mathrm{O}^{\bullet}$ & $(5.22 \pm 0.31) \times 10^{3}$ \\
\hline R7 & $\mathrm{DMM}+\mathrm{HO}^{\bullet} \rightarrow \mathrm{H}_{2} \mathrm{O}+\mathrm{CH}_{2}{ }^{\bullet} \mathrm{OCH}_{2} \mathrm{OCH}_{3}$ & $(1.27 \pm 0.16) \times 10^{3}$ \\
\hline R8 & $\mathrm{DMM}+\mathrm{CH}_{3} \mathrm{O}^{\bullet} \rightarrow \mathrm{CH}_{3} \mathrm{OCH}^{\bullet} \mathrm{OCH}_{3}+\mathrm{HOCH}_{3}$ & $(2.50 \pm 0.17) \times 10^{1}$ \\
\hline R9 & $\mathrm{MB} \rightarrow \mathrm{CH}_{3} \mathrm{O}^{\bullet}+\mathrm{CH}_{3}\left(\mathrm{CH}_{2}\right)_{2}\left(\mathrm{C}^{\bullet} \mathrm{O}\right)$ & $(1.78 \pm 0.15) \times 10^{3}$ \\
\hline R10 & $\mathrm{MB} \rightarrow \mathrm{CH}_{3}^{\bullet}+\mathrm{CH}_{3}\left(\mathrm{CH}_{2}\right)_{2}(\mathrm{CO}) \mathrm{O}^{\bullet}$ & $(5.00 \pm 0.27) \times 10^{2}$ \\
\hline R11 & $\mathrm{MB} \rightarrow \mathrm{CH}_{3} \mathrm{CH}_{2} \mathrm{CH}_{2}^{\bullet}+\mathrm{CH}_{3} \mathrm{O}\left(\mathrm{C}^{\bullet} \mathrm{O}\right)$ & $(1.54 \pm 0.11) \times 10^{2}$ \\
\hline $\mathrm{R} 12$ & $\mathrm{MB} \rightarrow \mathrm{CH}_{3} \mathrm{O}(\mathrm{CO}) \mathrm{CH}_{2}^{\bullet}+\mathrm{CH}_{3} \mathrm{CH}_{2}^{\bullet}$ & $(2.51 \pm 0.15) \times 10^{1}$ \\
\hline R13 & $\mathrm{MB}+\mathrm{H}^{\bullet} \rightarrow \mathrm{CH}_{3} \mathrm{CH}_{2} \mathrm{CH}^{\bullet}(\mathrm{CO}) \mathrm{OCH}_{3}+\mathrm{H}_{2}$ & $(3.77 \pm 0.20) \times 10^{0}$ \\
\hline R14 & Ethanol $\rightarrow{ }^{\bullet} \mathrm{OH}+\mathrm{CH}_{3} \mathrm{CH}_{2}{ }^{\bullet}$ & $(4.71 \pm 0.41) \times 10^{1}$ \\
\hline R15 & Ethanol $\rightarrow \mathrm{CH}_{2} \bullet \mathrm{OH}+\mathrm{CH}_{3}^{\bullet}$ & $(9.39 \pm 0.51) \times 10^{0}$ \\
\hline R16 & Ethanol $+{ }^{\bullet} \mathrm{OH} \rightarrow \mathrm{H}_{2} \mathrm{O}+\mathrm{CH}_{3} \mathrm{CH}_{2} \mathrm{O}^{\bullet}$ & $(0.99 \pm 0.09) \times 10^{0}$ \\
\hline R17 & Ethanol $\rightarrow{ }^{\bullet} \mathrm{H}+\mathrm{CH}_{2} \cdot \mathrm{CH}_{2} \mathrm{OH}$ & $(4.02 \pm 0.23) \times 10^{\circ}$ \\
\hline
\end{tabular}


consumption of oxygenates. Relevant pathways in DMM and ethanol produce $\mathrm{H}_{2} \mathrm{O}$, which affects the effectiveness of the O-atom in combining C-atoms to some extent and should not be ignored. From Table 2, it can be summarized that although oxygenates decompose primarily into oxygenated intermediates, they also produce methyl, ethyl, and propyl radicals as well as some biradicals, which in turn are likely to favour soot precursor production. For example, three of the MB pyrolysis pathways produce alkyl radicals, whereas in the case of DMC and DMM, only one methyl radical formation pathway is observed. In this manner, the consumption patterns of the additive can be expressed in two aspects, removing C-atoms from the soot precursor pool via combination with $\mathrm{O}$-atoms in functional groups while contributing to soot precursor formation due to the alkyl chains simultaneously.

\section{Conclusion}

The evolutions of regular emission products and unsaturated PAH precursors of diesel combustion are examined qualitatively and quantitatively using ReaxFF MD simulation. Cyclopentadienyl and benzene, generated from the precursors, tend to react into PAHs with five-, six- and seven-membered carbon rings via $\mathrm{C}_{2} \mathrm{H}_{2}$ or $\mathrm{C}_{2} \mathrm{H}_{3}$ addition. The substituted radicals favour the subsequent continuous mass growth by reacting with other resonantlystabilized radicals and saturated/unsaturated aliphatic species, producing the aromatic aliphatically linked hydrocarbons. In the ReaxFF simulation, these larger hydrocarbon clusters undergo coalescence through aliphatic chain connection. This process results in rapid mass growth and eventually leads to the condensed nascent soot particle, which is characterised by an amorphous structure, around $3.7 \mathrm{~nm}$ in diameter and $998 \mathrm{amu}$ in mass, a $\mathrm{C}: \mathrm{H}$ ratio in the range of $6-10$, and being rich in aliphatics, with an aliphatic-to-aromatic $\mathrm{C}: \mathrm{H}$ ratio of 2.3.

The effects of oxygenated molecular structures on soot formation are quantified and reflected in two aspects: removing $\mathrm{C}$-atoms from the soot precursor pool through combination with the O-atoms, and contributing to soot precursor formation due to the existence of $\mathrm{C}-\mathrm{C}$ bonds simultaneously. Regarding the soot formation propensity, the C-atoms from DMC and DMM are less likely than diesel to appear in incipient soot particles, while MB, CPO and ethanol show similar tendencies to that of diesel. The $\mathrm{C}=\mathrm{O}$ double bond in the carbonyl group is sufficiently stable to survive under the high-temperature condition and favours the formation of $\mathrm{CO}$ while the production of $\mathrm{CO}_{2}$ in $\mathrm{DMC}$ and $\mathrm{MB}$ is mainly due to $\mathrm{C}-\mathrm{O}$ fission between the ester moiety and the methyl group and the subsequent $\beta$-scission. The effect of oxygenated additives on the sooting propensity of diesel blends is the consequence of interactions of the oxygenated moiety and the aliphatics at the atomistic level.

\section{Conflicts of interest}

There are no conflicts of interest to declare.

\section{References}

1 A. K. Agarwal, J. G. Gupta and A. Dhar, Potential and challenges for large-scale application of biodiesel in automotive sector, Prog. Energy Combust. Sci., 2017, 61, 113-149.

2 C. K. Westbrook, W. J. Pitz and H. J. Curran, Chemical kinetic modeling study of the effects of oxygenated hydrocarbons on soot emissions from diesel engines, J. Phys. Chem. A, 2006, 110, 6912-6922.

3 P. Pepiot-Desjardins, H. Pitsch, R. Malhotra, S. Kirby and A. L. Boehman, Structural group analysis for soot reduction tendency of oxygenated fuels, Combust. Flame, 2008, 154, 191-205.

4 X. Mercier, O. Carrivain, C. Irimiea, A. Faccinetto and E. Therssen, Dimers of polycyclic aromatic hydrocarbons: the missing pieces in the soot formation process, Phys. Chem. Chem. Phys., 2019, 21, 8282-8294.

5 H. Wang, Formation of nascent soot and other condensedphase materials in flames, Proc. Combust. Inst., 2011, 33, 41-67.

$6 \mathrm{H}$. Michelsen, Probing soot formation, chemical and physical evolution, and oxidation: a review of in situ diagnostic techniques and needs, Proc. Combust. Inst., 2017, 36, 717-735.

7 J. P. Cain, J. Camacho, D. J. Phares, H. Wang and A. Laskin, Evidence of aliphatics in nascent soot particles in premixed ethylene flames, Proc. Combust. Inst., 2011, 33, 533-540.

8 B. Zhao, Z. Yang, Z. Li, M. V. Johnston and H. Wang, Particle size distribution function of incipient soot in laminar premixed ethylene flames: effect of flame temperature, Proc. Combust. Inst., 2005, 30, 1441-1448.

9 M. Keller, T. de Bruin, M. Matrat, A. Nicolle and L. Catoire, A Theoretical Multiscale Approach to Study the Initial Steps Involved in the Chemical Reactivity of Soot Precursors, Energy Fuels, 2019, 33, 10255-10266.

10 A. Violi, A. Kubota, T. Truong, W. Pitz, C. Westbrook and A. Sarofim, A fully integrated kinetic Monte Carlo/molecular dynamics approach for the simulation of soot precursor growth, Proc. Combust. Inst., 2002, 29, 2343-2349.

11 A. Violi, Modeling of soot particle inception in aromatic and aliphatic premixed flames, Combust. Flame, 2004, 139, 279-287.

12 A. Violi and A. Venkatnathan, Combustion-generated nanoparticles produced in a benzene flame: a multiscale approach, J. Chem. Phys., 2006, 125, 054302.

13 P. Elvati and A. Violi, Thermodynamics of poly-aromatic hydrocarbon clustering and the effects of substituted aliphatic chains, Proc. Combust. Inst., 2013, 34, 1837-1843.

14 J. S. Lowe, J. Y. Lai, P. Elvati and A. Violi, Towards a predictive model for polycyclic aromatic hydrocarbon dimerization propensity, Proc. Combust. Inst., 2015, 35, 1827-1832.

15 K. Bowal, J. W. Martin and M. Kraft, Partitioning of polycyclic aromatic hydrocarbons in heterogeneous clusters, Carbon, 2019, 143, 247-256.

16 Q. Mao, A. C. T. van Duin and K. H. Luo, Formation of incipient soot particles from polycyclic aromatic hydrocarbons: a ReaxFF molecular dynamics study, Carbon, 2017, 121, 380-388. 
17 Q. Mao, J. Zhou, K. H. Luo and A. C. T. van Duin, Atomistic insights into the dynamics of binary collisions between gaseous molecules and polycyclic aromatic hydrocarbon dimers, Phys. Chem. Chem. Phys., 2019, 21, 3849-3856.

18 Q. Mao, D. Hou, K. H. Luo and X. You, Dimerization of polycyclic aromatic hydrocarbon molecules and radicals under flame conditions, J. Phys. Chem. A, 2018, 122, 8701-8708.

19 C. Ashraf and A. C. T. van Duin, Extension of the ReaxFF combustion force field toward syngas combustion and initial oxidation kinetics, J. Phys. Chem. A, 2017, 121, 1051-1068.

20 C. Ashraf, S. Shabnam, A. Jain, Y. Xuan and A. C. T. van Duin, Pyrolysis of binary fuel mixtures at supercritical conditions: a ReaxFF molecular dynamics study, Fuel, 2019, 235, 194-207.

21 X. Z. Jiang, M. Feng, W. Zeng and K. H. Luo, Study of mechanisms for electric field effects on ethanol oxidation via reactive force field molecular dynamics, Proc. Combust. Inst., 2019, 37, 5525-5535.

22 S. G. Srinivasan, A. C. T. van Duin and P. Ganesh, Development of a ReaxFF potential for carbon condensed phases and its application to the thermal fragmentation of a large fullerene, J. Phys. Chem. A, 2015, 119, 571-580.

23 Y. Qian, L. Yu, Z. Li, Y. Zhang, L. Xu and Q. Zhou, et al., A new methodology for diesel surrogate fuel formulation: bridging fuel fundamental properties and real engine combustion characteristics, Energy, 2018, 148, 424-447.

24 Z. Chen, W. Sun and L. Zhao, Combustion mechanisms and kinetics of fuel additives: a ReaxFF molecular simulation, Energy Fuels, 2018, 32, 11852-11863.

25 S. Shabnam, Q. Mao, A. C. T. van Duin and K. H. Luo, Evaluation of the effect of nickel clusters on the formation of incipient soot particles from polycyclic aromatic hydrocarbons via ReaxFF molecular dynamics simulations, Phys. Chem. Chem. Phys., 2019, 21, 9865-9875.

26 S. Plimpton, Fast parallel algorithms for short-range molecular dynamics, J. Comput. Phys., 1995, 117, 1-19.

27 M. Döntgen, M.-D. Przybylski-Freund, L. C. Kröger, W. A. Kopp, A. E. Ismail and K. Leonhard, Automated discovery of reaction pathways, rate constants, and transition states using reactive molecular dynamics simulations, J. Chem. Theory Comput., 2015, 11, 2517-2524.

28 W. Humphrey, A. Dalke and K. Schulten, VMD: visual molecular dynamics, J. Mol. Graphics, 1996, 14, 33-38.

29 Z. Chen, W. Sun and L. Zhao, Initial mechanism and kinetics of diesel incomplete combustion: ReaxFF molecular dynamics based on a multicomponent fuel model, J. Phys. Chem. C, 2019, 123, 8512-8521.

30 C. S. McEnally, L. D. Pfefferle, B. Atakan and K. KohseHöinghaus, Studies of aromatic hydrocarbon formation mechanisms in flames: progress towards closing the fuel gap, Prog. Energy Combust. Sci., 2006, 32, 247-294.

31 S. V. Kalpathy, N. B. Poddar, S. P. Bagley and M. J. Wornat, Reaction pathways for the growth of polycyclic aromatic hydrocarbons during the supercritical pyrolysis of $n$-decane, as determined from doping experiments with 1-and 2-methylnaphthalene, Proc. Combust. Inst., 2015, 35, 1833-1841.

32 C. Shaddix, K. Brezinsky and I. Glassman, Analysis of fuel decay routes in the high-temperature oxidation of 1-methylnaphthalene, Combust. Flame, 1997, 108, 139-157.

33 F. Schulz, M. Commodo, K. Kaiser, G. De Falco, P. Minutolo and G. Meyer, et al., Insights into incipient soot formation by atomic force microscopy, Proc. Combust. Inst., 2019, 37, 885-892.

34 A. Farooq, W. Ren, K. Y. Lam, D. F. Davidson, R. K. Hanson and C. K. Westbrook, Shock tube studies of methyl butanoate pyrolysis with relevance to biodiesel, Combust. Flame, 2012, 159, 3235-3241.

35 W. Sun, C. Huang, T. Tao, F. Zhang, W. Li and N. Hansen, et al., Exploring the high-temperature kinetics of diethyl carbonate (DEC) under pyrolysis and flame conditions, Combust. Flame, 2017, 181, 71-81.

36 W. Sun, T. Tao, H. Liao, N. Hansen and B. Yang, Probing fuel-specific reaction intermediates from laminar premixed flames fueled by two C5 ketones and model interpretations, Proc. Combust. Inst., 2019, 37, 1699-1707. 